\title{
Analysis of Equivalence and Reliability of Korean Translated Abbreviated Profile of Hearing Aid Benefits
}

\author{
Taehwa Kim", Jinsook Kim ${ }^{1,2}$ \\ 'Department of Speech Pathology and Audiology, Graduate School, Hallym University, Chuncheon, Korea \\ ${ }^{2}$ Division of Speech Pathology and Audiology, Research Institute of Audiology and Speech Pathology, College of Natural Sciences, Hallym University, \\ Chuncheon, Korea
}

\author{
Received: March 18, 2020 \\ Revised: May 18, 2020 \\ Accepted: May 22, 2020 \\ Correspondence: \\ Jinsook Kim, PhD \\ Division of Speech Pathology and \\ Audiology, Research Institute of \\ Audiology and Speech Pathology, \\ College of Natural Sciences, \\ Hallym University, 1 Hallymdaehak-gil, \\ Chuncheon 24252, Korea \\ Tel: +82-33-248-2213 \\ Fax: +82-33-256-3240 \\ E-mail: jskim@hallym.ac.kr
}

For using the translated questionnaires, an appropriate translation should be accomplished for establishing the equivalence. The equivalence is divided into two categories, formal equivalence regarding words and grammar and dynamic equivalence meaning the naturalness of the context with the consideration of the cultural and emotional characteristics of the region. The purpose of this study was to verify formal and dynamic equivalences and statistical reliability of the widely used translated questionnaire in Korea, abbreviated profile of hearing aid benefits (APHAB). The identification of equivalence was conducted in formal and dynamic categories and the statistical verification was performed for 6 translated APHAB which are currently utilized in Korea. None of 6 translated APHAB had formal and dynamic equivalences for all 24 items when the score ' 2 ' was given to the completed equivalence of each item. Two translated APHAB showed ' 11 ' as the best score and one of them showed ' $O$ ' for the formal equivalence identification. For the dynamic equivalence, the two translated APHAB scored ' 20 ' as the best score. The one scored ' 0 ' for the formal equivalence showed ' 0 ' also in the dynamic equivalence. And only two translated APHAB presented the statistical validation using Cronbach's alpha and factor analysis. It was confirmed that any of 6 translated APHAB in Korea could not reproduce the original contents with the appropriate equivalence and statistical validation. As the translated version was found to have a limitation in delivering the original contents due to language, emotional and cultural differences, a Korean questionnaire should be developed.

Key Words: Abbreviated profile of hearing aid benefits, Equivalence, Questionnaire, Reliability, Translation.

\section{INTRODUCTION}

청각장애와 관련된 연구와 임상에서는 보청기 착용 관련 만 족도, 보청기 적응 및 수행능력, 스스로 느끼는 청각장애 정도 등에 대한 객관적 지표를 확인하기 위하여 설문지를 이용한 평 가가 널리 사용되고 있다. 설문지 평가는 난청인 본인이 실질적 으로 부딪히는 문제와 상황에 대해 스스로 답한 내용을 객관 적인 자료로 사용할 수 있다는 장점이 있다(Han et al., 2015). 그러나 평가지를 개발하려면 오랜 시간 방대한 자료를 수집하 여야 하고 그에 따른 비용이 상당히 소요되는 단점도 있다. 따 라서 새로운 평가 방법을 개발하기보다는 외국의 설문지를 한 국어로 번역하여 사용하는 경우가 많다. 번역된 설문지를 사용

(c) This is an Open Access article distributed under the terms of the Creative Commons Attribution Non-Commercial License (https://creativecommons.org/licenses/by-nc/4.0) which permits unrestricted non-commercial use, distribution, and reproduction in any medium, provided the original work is properly cited.
하려면 원본과 견주어 타당하고 정확한 결과를 끌어내기 위하 여 설문 결과의 오류를 최소화할 수 있는 적절한 번역 절차를 거쳐야 한다(Chapman \& Carter, 1979).

적절한 번역 절차는 개발자에게 연락하여 번역에 대한 동의 를 구한 뒤 번역할 언어로 순번역한 다음, 해당 언어로 역번역 하는 과정을 거쳐야 한다. 이런 과정을 거쳐 번역한 내용이 원 본과 일치하는지 확인할 수 있다. 이후 전문가에게 내용 타당 도를 검증받고 문항의 오류를 확인하는 연구를 진행하여 오류 문항을 수정한다. 마지막으로 신뢰도와 타당도를 검증하고 원 본과 유사한지 비교하여 최종 번역본을 완성하면 우수한 번역 본으로 사용이 가능하다(Jang, 2014). 이 과정에서 번역본을 사용할 지역의 문화와 언어를 원본이 나온 지역과 비교하고 그 차이를 이해하여 해당 지역 사회의 특정 정서를 반영한 원본 내용이 번역본에 올바르게 전달되었는지 확인하여야 한다 (Kim et al., 2017). 설문지는 언어와 문화적 배경에 따라 문항의 
해석이 달라질 수 있다. 그러므로 각 언어와 문화 및 정서에 맞는 적절한 용어를 선택하여 설문 문항의 등가성(equivalence)을 확 보하여야 한다. 등가성이라는 개념은 원본과 번역본의 내용이 동 일한 차원에 위치하는 것으로 정의할 수 있으므로, 등가성이 확 보되어야 외국의 원본 자료로 얻은 결과와 비교가 가능하다 (Lee, 2004).

설문 문항의 등가성을 분류하는 방법으로는 연구자에 따라 여러 가지 논의들이 있다. 처음 등가성의 이론을 정립한 Jakob$\operatorname{son}(1959)$ 은 언어적 관점에서만 설명하였으나, 이후 Nida(1964) 는 의사소통의 관점에서 형식적 및 역동적 등가성으로 나누어 정의하여 구체적인 등가 개념을 확립하였다. 형식적 등가는 형 태나 내용상 전달하고자 하는 그 자체에 초점을 맞추어 문법과 단어가 일치하고 문항의 형식이 동일하여 원본의 의미가 재현 되는 것을 의미한다. 역동적 등가는 번역된 언어에 초점을 맞추 어 번역본이 그 언어를 사용하는 환경의 문화와 정서를 반영하 고 부드러운 맥락의 문장으로 자연스럽게 읽히는 것까지도 포 함한다.

역동적 등가는 세부적으로 문맥적 및 문화적 등가로 나뉘는 데, 문맥적 등가는 번역된 단어의 적절성, 맥락의 유연성, 선택 된 단어의 의미적 일치성 등을 의미하며 특히 번역 시 단어의 선정이 중요함을 강조한다(Lee, 2015). 이는 그 언어를 사용하 는 특정 사회나 지역 혹은 문화에 따라 언어가 내포하는 의미 에 차이가 있고 문화와 정서에 따라 관용적 의미가 다르기 때 문이다. 예를 들어 여러 가지 단어가 그 의미를 뜻하는 경우 그 중 하나의 단어를 선택하여 의미를 정확히 전달하고자 할 때 많은 생각이 필요할 수 있다. 더욱이 단어의 이해 정도와 설문 의 구체적 수준이 차이가 나거나(Hur, 1998), 설문 내용의 중점 사안은 동일하지만 설문 문항의 상세 내용이 다르게 이해될 경 우 응답 결과는 차이가 나타날 수도 있다(Shin et al., 2007). 언 어는 특히 문화와 깊은 관계가 있으므로 문화적 등가도 고려하 여야 한다. 문화적 차이를 무시하고 설문 문항을 번역하면 원래 개발자가 의도했던 것과는 다른 내용으로 번역될 수 있기 때문 이다. 원본이 개발된 지역과 번역본이 사용될 지역의 문화를 모 두 이해하고 양측 문화적 배경에 대한 지식과 이해를 바탕으로 번역본이 제작되어야 한다. 따라서 이러한 요소를 고려하여 원 본의 의도와 내용을 훼손하지 않는 범위에서 번역본을 제작하 고자 하는 노력이 필요하다(Ko, 2006).

그러나 개념의 동등성과 내용의 일치성을 확인하여 등가성 이 확보되었다고 해서 번역본이 원본과 동일 수준의 신뢰도와 타당도를 확보한 것은 아니다. 신뢰도는 측정하고자 하는 내용 을 얼마나 정확하게 측정하였는지를 확인하는 일관성을 의미 하고, 타당도는 측정 도구로써 측정하고자 하는 내용을 실제로 잘 측정하는지에 대하여 검증하는 것을 의미한다. 대부분 신뢰
도 검증을 위해서 Cronbach's $\alpha$ 를 이용한 내적 일관성 신뢰도 분석과 피어슨 상관계수를 통한 검사-재검사 신뢰도가 사용된 다(Lee \& Shin, 2013). 내적 일관성을 확인하기 위하여 사용되는 신뢰도 지수인 Cronbach's $\alpha$ 는 0.9 이상이면 매우 높은 신뢰도 로, 0.8 이상이면 바람직한 신뢰도로, 0.7 이상이면 수용 가능한 신뢰도로, 0.6 이상이면 의심스러운 신뢰도로, 0.5 이상이면 좋지 못한 신뢰도로, 0.5 이하이면 받아들일 수 없는 신뢰도로 생각된 다(George \& Mallery, 2003). 검사-재검사 신뢰도는 비교적 정 밀하게 개인의 점수 차이를 보고자 할 때는 0.9 이상이 되어야 하지만 일반적으로는 0.7 이상이면 유용성이 있는 적절한 신뢰 도를 확보한 설문지로 인정한다(Guilford \& Fruchter, 1978).

타당도를 검증하는 방법으로 내용 타당도, 준거 타당도, 구 성 타당도 등이 있다. 이 중 내용 타당도는 각 문항이 평가하고 자 하는 목적을 얼마나 충실하게 측정하고 있는지를 의미하며 해당 분야에 대한 전문가의 판단으로 규정하고, 준거 타당도는 설문으로 나타난 결과가 다른 기준 지표를 사용한 결과와 비교 했을 때의 관련성을 확인하며(Kim et al., 2008), 구성 타당도 는 측정하고자 하는 개념이 제대로 측정되고 있는지를 확인한 다(Kang, 2013). 청각학 관련 연구에서 많이 활용하는 타당도 의 검증 방법은 요인 분석(factor analysis)으로 측정 변수들로 부터 잠재 변수를 발견해 내는 통계적 과정을 거쳐 구성 타당 도를 검증한다. 타당도와 신뢰도의 관계에서 타당도가 높으려 면 신뢰도가 높아야 하지만, 신뢰도가 높다고 해서 반드시 타 당도가 높은 것은 아니다. 이는 상호 연관성은 있으나 서로 다 른 개념이기 때문이다(Seong, 2002).

현재 국내에서 사용되는 청각장애와 관련한 설문지의 주요 번역본을 Table 1에 정리하였다. 이 중 hearing handicap inventory for the elderly (Ku \& Kim, 2000; Park et al., 2011) 와 2004년 김진숙 교수가 번역하고 홈페이지에 소개된 international outcome inventory for hearing aids (https://icraaudiology.org/Repository/self-report-repository/IOI-HAquestionnaires/korean)는 타당한 번역 절차를 거쳐 효용성 있 는 검사 도구로 국내외에서 이미 널리 활용되고 있고 원본과 직 접적으로 비교 분석이 가능하다(Chu et al., 2012). 그러나 적절 한 검증 과정을 거치지 않거나 국내의 상황과 정서가 제대로 반영되고 있지 않아 신뢰도와 타당도가 떨어지는 번역본도 존 재한다. 예를 들어 Cox \& Alexander(1999)의 Satisfaction with Amplification in Daily Life (SADL)의 번역본은 원저자 의 동의로 순번역과 역번역 절차를 거쳐 번역본을 완성하였다. 하지만 하위항목 중 '개인적 이미지' 영역에서 원본의 평균 점 수는 0.66 인데 번역본은 0.29 로 차이가 크게 나타났다. 저자는 그 원인을 문화와 정서적 차이에 따른 문항 해석의 차이로 생 각된다고 하였다(Kim et al., 2018). 또한 Jo et al.(2011)의 atti- 
Table 1. Important translated hearing related questionnaires for Korean version

\begin{tabular}{|c|c|c|}
\hline Questionnaire & Developers & Korean version of questionnaire \\
\hline Hearing handicap inventory for the elderly & Ventry \& Weinstein (1982) & $\begin{array}{l}\text { - Ku \& Kim (2000) } \\
\text { - Park et al. (2011) }\end{array}$ \\
\hline Attitudes toward loss of hearing questionnaire & Saunders \& Cienkowski (1996) & - Jo et al. (2011) \\
\hline International outcome inventory for hearing aids & Cox \& Alexander (2002) & $\begin{array}{l}\text { - Translated by Jinsook Kim (2004) } \\
\text { - Chu et al. (2012) }\end{array}$ \\
\hline Speech, spatial and qualities of hearing scale & Gatehouse \& Noble (2004) & - Heo \& Lee (2009) \\
\hline Satisfaction with amplification in daily life & Cox \& Alexander (1999) & - Kim et al. (2018) \\
\hline Abbreviated profile of hearing aid benefits & Cox \& Alexander (1995) & $\begin{array}{l}\text { - Yun et al. (2000) } \\
\text { - Lim et al. (2017) }\end{array}$ \\
\hline
\end{tabular}

tudes toward loss of hearing questionnaire (ALHQ) 번역본 은 신뢰도와 타당도가 원본과 비교 시 현저하게 낮게 나타났 다. 저자들은 심리적 내용을 포함하는 문항이 많아 번역 시 원 본의 내용을 그대로 재현하기 어려웠던 점을 본 번역본의 제한 점으로 보고하였다.

국내외에서 보청기 착용 효과를 평가하고 청각 재활에도 널 리 사용되는 설문지 중 하나인 Cox \& Alexander(1995)의 abbreviated profile of hearing aid benefits (APHAB)는 상이하게 번역된 여러 개의 번역본이 국내에서 사용되고 있다. APHAB은 profile of hearing aid performance (PHAP)와 profile of hearing aid benefit (PHAB)을 기반으로 개발된 설문지이다. PHAP 과 $\mathrm{PHAB}$ 은 일상생활 중 다양한 상황에서 의사소통능력과 환 경음의 음질과 크기에 대한 반응을 측정하기 위하여 보청기 착 용 후 경험을 정량화할 수 있도록 개발되었다. Familiar talkers (FT, 친숙한 화자), ease of communication (EC, 쉬운 의사소 통), reverberation (RV, 반향음이 있는 상황), reduced cues ( $\mathrm{RC}$, 단서가 적은 상황), background noise ( $\mathrm{BN}$, 소음이 존재 하는 상황), aversiveness of sounds ( $\mathrm{AV}$, 크고 날카로운 음), distortion of sounds (DS, 소리의 왜곡) 등의 7개 항목으로 구 성되었다. 설문에 대한 응답은 7단계의 리커트 반응척도로 '항 상(always), 거의 항상(almost always), 대체로(generally), 절반 정도(half-the-time), 가끔(occasionally), 드물게(seldom), 전혀 아니다(never)' 중 하나를 선택하여 답변하도록 되어 있다.

$\mathrm{PHAP}$ 가 보청기를 착용하였을 때의 수행능력만을 측정한다 면, $\mathrm{PHAB}$ 은 '보청기를 착용하였을 때(with my hearing aid)' 와 '보청기를 착용하지 않았을 때(without my hearing aid)'로 구분하여 보청기 착용 전과 후의 수행능력의 변화와 보청기 착 용 후 이득을 측정할 수 있도록 제작하였다. 그러나 두 설문지 모두 항목과 문항의 수가 많아 임상적으로 사용하는 데 시간 이 오래 걸려 집중력을 잃기 쉬운 단점이 있다. 특히 항목 FT는 비교적 쉬운 의사소통 상황과 관련된 항목이기에 결과로 천정 효과(ceiling effect)가 나타났고, 항목 DS와 RC는 통계 분석
결과 내적 일관성 신뢰도와 검사-재검사에서 신뢰할 수 있는 수치보다 낮은 점수 결과를 보였다(Cox et al., 1991). 따라서 $\mathrm{FT}, \mathrm{DS}, \mathrm{RC}$ 등 세 개의 항목을 삭제한 후 $\mathrm{EC}, \mathrm{BN}, \mathrm{RV}, \mathrm{AV}$ 항 목 4개로 축소하고 66문항이었던 문항 수를 24개로 줄여서 임 상에서 쉽고 빠르게 사용할 수 있도록 축약된(abbreviated) $\mathrm{PHAB}$ 인 $\mathrm{APHAB}$ 이 개발되었다.

$\mathrm{APHAB}$ 은 $\mathrm{PHAB}$ 과 동일하게 일곱 단계의 리커트 반응척 도를 사용하고 구성이 간단하다. 따라서 많은 사람을 대상으로 쉽고 정확하게 사용할 수 있고 결과를 곧바로 수치화하여 임상 에 활용할 수 있는 장점이 있다(Kim, 2011). 새로이 구성된 $\mathrm{APHAB}$ 의 타당도 검증으로 요인 분석을 실시하였는데 $\mathrm{EC}$ 와 $\mathrm{AV}$ 항목은 각 항목에 대한 문항들이 잘 묶여진 결과를 보였으 나 $\mathrm{BN}$ 과 RV 항목은 명확하게 분류되지 않았다(Cox \& Gilmore, 1990). 이에 대하여 저자들은 소음이 있거나 반향이 있는 비교적 듣기 어려운 상황에서 난청인이 보청기를 착용하였을 때 듣기의 어려움이 비슷한 것으로 설명하였다. 신뢰도 분석으 로 Cronbach's $\alpha$ 값을 보청기 착용 전, 보청기 착용 후, 보청기 착용 전과 후의 이득(benefit)에서 측정하였을 때 모든 항목에 서 0.7 보다 높게 나타났다. 검사-재검사 분석에서는 보청기 착 용 전의 $\mathrm{RV}$ 항목과 보청기 착용 후의 $\mathrm{BN}$ 항목이 0.65 와 0.67 이었고 보청기 착용 전과 후의 이득에서 $\mathrm{EC}, \mathrm{RV}, \mathrm{BN}$ 항목은 0.48 에서 0.58 이었다. 그 외 다른 항목에서는 모두 0.7 이상으로 신뢰도는 어느 정도 확보된 설문 도구로 인정받았다(Table 2).

이렇게 4 개의 항목과 총 24 개 문항으로 구성된 $\mathrm{APHAB}$ 은 보청기 착용 전 점수로 보청기 착용의 성공을 예측하고, 보청 기 착용 후 환경에 따라 서로 다른 소리 조절능력을 비교할 수 있고, 이득을 정량화할 수 있는 장점이 있어(Cox, 1997) 널리 사 용되고 있다. 더욱이 보청기 착용 후 서로 다른 피팅 포뮬라를 비교하고 동일한 보청기의 이중 마이크 성능도 비교할 수 있어 보청기 재활 효과를 측정하고 청능 훈련 효과를 측정할 수 있는 매우 유용한 도구이다(Kim \& Lee, 2017; Shabana et al., 2017). 우리나라 Korean Industrial Standards (KS) 표준에서도 보청기 
Table 2. Cronbach's alpha and test-retest reliability of the four abbreviated profile of hearing aid benefits subscales adapted from Cox \& Alexander (1995)

\begin{tabular}{|c|c|c|c|c|c|c|}
\hline \multirow{2}{*}{$\begin{array}{l}\text { Subscale } \\
\text { category }\end{array}$} & \multicolumn{2}{|c|}{ Unaided } & \multicolumn{2}{|c|}{ Aided } & \multicolumn{2}{|c|}{ Benefit } \\
\hline & Cronbach's $a$ & Test-retest reliability & Cronbach's $\alpha$ & Test-retest reliability & Cronbach's $\alpha$ & Test-retest reliability \\
\hline $\mathrm{EC}$ & 0.87 & 0.80 & 0.84 & 0.76 & 0.79 & 0.54 \\
\hline RV & 0.83 & 0.65 & 0.85 & 0.81 & 0.78 & 0.50 \\
\hline $\mathrm{BN}$ & 0.82 & 0.71 & 0.85 & 0.67 & 0.80 & 0.48 \\
\hline $\mathrm{AV}$ & 0.86 & 0.89 & 0.85 & 0.70 & 0.82 & 0.71 \\
\hline
\end{tabular}

EC: ease of communication, RV: reverberation, BN: background noise, AV: aversiveness of sounds

의 주관적 이득을 확인하는 지표로 $\mathrm{APHAB}$ 이 언급되었고, $\mathrm{KS}$ 문서에 Korean version of profile of hearing aid benefits $\left(\mathrm{K}^{-}\right.$ $\mathrm{PHAB}$ ) (Kim et al., 2016)가 국내에서 번역된 APHAB을 대표하 는 참고문헌으로 소개되었다. 그러나 $\mathrm{K}-\mathrm{PHAB}$ 은 $\mathrm{APHAB}$ 을 그 대로 번역하지 않았고 대부분의 문항을 재구성하고 18 개의 문 항을 삭제하고 1 개 항목(localization, LC)과 14개의 문항을 새 로운 내용으로 추가하여 총 문항은 20문항으로 총 문항이 24문 항인 $\mathrm{APHAB}$ 의 번역본으로 보기는 어렵기 때문에 $\mathrm{K}-\mathrm{PHAB}$ 이 라는 명칭이 부적절하다고 생각된다.

현재 국내에서 사용되고 있는 $\mathrm{APHAB}$ 번역본은 Yun et al.(2000)과 Lim et al.(2017)이 발표한 번역본, 한림국제대학원 대학교 청각언어연구소에서 자체적으로 제작하여 사용하고 있 는 번역본(Yeo et al., 2014), 알고코리아에서 번역하여 인터넷 을 통해 소개된 번역본(https://cafe.naver.com/digitalhearin$\mathrm{gaid} / 9)$, 스타키코리아에서 자체적으로 번역하여 사용하고 있 는 번역본(Appendix) 등 5개가 있다. $\mathrm{APHAB}$ 은 보청기 착용 전후 효과를 정량적 평가로 분석할 수 있으므로 국내 보청기 착용 효과를 분석하고 이를 국제적으로 비교할 수 있으므로 번 역본의 등가성이 더욱 중요하다. 따라서 본 연구는 기존에 사 용되고 있는 국내 $\mathrm{APHAB}$ 번역본의 등가성 및 신뢰도를 비교 분석하고 청각학 분야의 설문지의 번역본 사용에 대한 적절성 을 논하고자 한다.

\section{ANALYSIS OF QUESTIONNAIRES}

\section{문항별 등가성 분석}

국내에서 $\mathrm{APHAB}$ 번역본으로 명명된 6개 설문지 $(\mathrm{A}, \mathrm{B}, \mathrm{C}$, $\mathrm{D}, \mathrm{E}, \mathrm{F})$ 의 등가성을 확인하기 위해 문항별로 형식적 및 역동 적 등가성을 분석하였다. 청각학 박사 과정생 1 명과 청각학 교 수 1 명이 원본 영문 문항과 한국어 번역본 문항을 함께 읽고 등 가성을 확인하는 과정을 거쳤다. 의견의 불일치가 있을 때는 Jeong(2009), Lee(2004), Lee(2015), Nida(1964) 연구의 등가성 개념에 맞추어 재분석하여 의견 조율 절차를 거쳤다. 각 6 개 번 역본에 대한 번역 진행 과정과 신뢰도를 확인하기 위한 통계적 분석 시행 여부는 Table 3에 정리하였다. 등가성 분석 시 원본
Table 3. Translation process and statistical verification of the Korean version of $A P H A B$

\begin{tabular}{cll}
\hline $\begin{array}{c}\text { Korean } \\
\text { APHAB }\end{array}$ & \multicolumn{1}{c}{ Translation process } & Statistical verification \\
\hline A & Not provided & Not provided \\
B & Forward \& backward translation & Done properly \\
C & Not provided & Not provided \\
D & Not provided & Not provided \\
E & Not provided & Not provided \\
F & Not provided \& reconstituted & Done properly \\
\hline
\end{tabular}

APHAB: abbreviated profile of hearing aid benefits

에 표현된 'I'는 한국어 문장 구조 특성상 생략하여 번역하지 않는 경우가 많아 ‘I'에 대한 번역 여부는 형식적 등가성을 침해 하지 않는 것으로 결정하였다(Oh \& Park, 2011).

문항 1: When I am in a crowded grocery store, talking with the cashier, I can follow the conversation

$\mathrm{A}$ 는 "혼잡한 시장에서 종업원이 하는 말을 잘 알아듣는다." $\mathrm{B}$ 는 "나는 혼잡한 식품 매장에서 계산을 할 때 잘 알아들을 수 있습니다." $\mathrm{C}$ 는 "혼잡한 백화점이나 마트에서 점원의 대화 를 이해할 수 있다." $\mathrm{D}$ 는 “사람으로 붐비는 채소 가게에서 계산 점원과 말할 때 대화를 따라갈 수 있다." $\mathrm{E}$ 는 "사람이 붐비는 채 소 가게에서 계산 점원과 말할 때 대화를 따라갈 수 있다.” $\mathrm{F}$ 는 "혼잡한 상점 또는 마트에서 점원이 하는 말을 이해할 수 있다." 로 번역하였다. 단어와 문법이 일치하는 번역본은 찾을 수 없어 모든 번역본에서 형식적 등가성이 확보되지 않았고 $\mathrm{D}$ 와 $\mathrm{E}$ 는 문맥상 뜻이 원본과 유사하고 문맥적·문화적 요소를 고려할 때 역동적 등가성이 확보된 것으로 나타났다. 그 외 번역본들 은 표현이 원본에서 의도했던 의미와 다르게 번역되어 있었다. 예를 들면 'grocery store'는 '식품 매장'을 의미하지만 문화적 차 이로 $\mathrm{A}, \mathrm{C}, \mathrm{D}, \mathrm{E}, \mathrm{F}$ 에서 '시장', ‘백화점', ‘채소 가게', '상점’ 등으 로 번역되었고, B는 'talking with the cashier'를 이야기할 때라 는 듣기 환경이 고려되지 않고 '계산을 할 때'로 번역되어 원본 의 의미가 재현되지 못하여 등가성을 확보하지 못하였다. 
문항 2: I miss a lot of information when I'm listening to a lecture

$\mathrm{A}$ 는 "강의나 수업 중 많은 내용을 놓친다." $\mathrm{B}$ 는 "나는 강의 나 수업을 들을 때 많은 내용을 놓칩니다." C는 "강의를 들을 때 많은 내용을 놓친다." $\mathrm{D}$ 와 $\mathrm{E}$ 는 "강의를 들을 때 많은 정보 를 놓친다." F는 "큰 강의실에서 강의를 들을 때 많은 내용을 놓치곤 한다.”로 번역하였다. C, D, E는 문법과 단어가 비교적 일치하여 형식적 등가성을 확보하였고, 역동적 등가성은 $\mathrm{C}$ 만이 번역된 문항이 자연스럽게 읽히고 이해되어 확보된 것으로 나 타났다. 그 외의 번역본들에서 등가성이 확보되지 못한 이유는 부적절한 단어 선택이나 원본에 없는 내용이 추가되었기 때문 이었는데, 예를 들면 D와 E에서 'information'이란 단어를 '정 보'로 직접적으로 해석하여 문맥적·문화적 등가성을 확보하지 못하였고, $\mathrm{A}, \mathrm{B}, \mathrm{F}$ 는 원본에 나타나지 않은 불필요한 단어인 '강의나 수업' 혹은 '큰'을 추가하였다.

문항 3: Unexpected sounds, like a smoke detector or alarm bell are uncomfortable

$\mathrm{A}$ 는 "화재 경보나 자명종과 같은 갑작스런 소리를 듣게 되면 불편하다." $\mathrm{B}$ 는 "화재 경보기나 또는 자명종과 같은 갑작스러 운 소리가 불쾌합니다." C는 "자동차 경적음과 같은 원치 않은 큰 소리를 들으면 불편하다." $\mathrm{D}$ 는 "가스 검출기나 화재 알람기 등에서 발생하는 예기치 않은 소리가 편하게 들리지 않는다." $\mathrm{E}$ 는 "가스 검출기나 화재 경보기에서 발생하는 예기치 못한 소 리가 편하게 들리지 않는다." F는 "비상 벨 소리같이 예기치 못 한 큰 소리를 들으면 몹시 불편하다.”로 번역하였다. $\mathrm{B}$ 는 형식적 등가성을 확보하였고, 역동적 등가성은 $\mathrm{A}, \mathrm{B}, \mathrm{D}, \mathrm{E}$ 에서 어느 정 도 확보되었다. 그러나 C와 F는 'smoke detector or alarm bell' 을 '자동차 경적음과 같은, '비상 벨 소리같이'로 번역하여 원본 과 의미가 달라져서 역동적 등가성을 확보하지 못하였다.

문항 4: I have difficulty hearing a conversation when I'm with one of my family at home

$\mathrm{A}$ 는 "집에서 가족과 대화할 때 청력장애를 느낀다." $\mathrm{B}$ 는 "나 는 집에서 가족 중 한 명과 대화할 때 어려움이 있습니다." C는 "집에서 가족 중 한 사람과 대화를 할 때 듣는 데 어려움이 있 다." $\mathrm{D}$ 는 "집에서 가족 중 한 사람과 있을 때 대화에 어려움을 가진다." E는 "집에서 가족 중 한 사람과 있을 때 대화에 어려 움을 느낀다.”로 번역하였다. C는 형식적 및 역동적 등가성이 충족되었고, $\mathrm{B}$ 는 원본에서 의도했던 맥락이 유사하여 역동적 등가성을 확보하였다. A, B, D, E는 'difficulty hearing'을 '듣기 에 어려움이라 번역하지 않고 ‘청각장애’ 또는 ‘어려움으로 번역 하여 원본과 의미가 다를 뿐 아니라 비교적 문맥상 자연스럽지
도 않았다. F는 본 문항을 삭제하여 문장 자체가 번역되지 않 아 설문지의 형식적 등가성이 완전히 결여되었다.

문항 5: I have trouble understanding dialogue in a movie or at the theater

$\mathrm{A}$ 는 "극장에 간 경우 영화에서 들리는 우리말 대사를 이해하 기 어렵다." B는 "나는 영화관이나 공연장에서 대사를 이해하 는 데 어려움이 있습니다." C는 "텔레비전 또는 영화의 대사를 잘 알아듣지 못한다." D와 $\mathrm{E}$ 는 "영화관이나 극장에서 대화를 이해하기가 어렵다." F는 "극장에서 영화를 볼 때 한국 배우의 말을 이해하기 어렵다.”로 번역하였다. B는 형식적 및 역동적 등 가성을 모두 확보하였으나, $\mathrm{A}$ 와 $\mathrm{C}$ 는 "in a movie or at the theater'를 '극장에 간 경우’와 ‘텔레비전'으로 바꾸어 번역하였고, D 와 E는 영화나 연극에 나오는 대사를 뜻하는 'dialogue'를 '대화' 로 번역하여 영화나 연극의 대사가 아니라 일반적인 대화로 오 해할 수가 있어 원본에서 의도하고자 했던 의미가 제대로 재현 되지 못하였다. F는 본 문항의 어구 중 "in a movie or at the theater'와 'dialogue'를 ‘극장에서 영화를 볼 때', '한국 배우의 말'이라고 번역하고 재구성하여 등가성을 확보하지 못하였다.

문항 6: When I am listening to the news on the car radio, and family members are talking, I have trouble hearing the news

$\mathrm{A}$ 는 "차 안에서 라디오 뉴스를 들을 때, 차 안의 누가 말을 하면 뉴스를 알아듣기가 어렵다." B는 "나는 차 안에서 뉴스를 들을 때 식구들이 말을 하면 라디오의 뉴스를 듣기가 어렵습니 다." C는 "차 안에서 라디오를 들을 때 다른 사람들이 떠들면 뉴스를 알아듣기 힘들다." $\mathrm{D}$ 는 "자동차 안에서 라디오를 듣는 데 가족들이 말하고 있으면 뉴스를 청취하기가 어렵다." $\mathrm{E}$ 는 "자동차 안에서 라디오 뉴스 청취 중 가족들이 대화를 나누고 있다면 뉴스를 청취하기가 어렵다.”로 번역하였다. 어떠한 번역 본도 형식적 등가성을 확보하지 못하였으나, $\mathrm{B}, \mathrm{D}, \mathrm{E}$ 는 원본의 의미와 유사하게 번역되어 역동적 등가성을 충족하였다. $\mathrm{A}$ 와 $\mathrm{C}$ 는 'family members'를 '식구' 혹은 '가족 구성원'으로 번역하지 않아 원본에서 의미하는 가족 간의 대화를 '누가' 혹은 '다른 사람들이 떠들면'으로 번역하여 원본의 의미가 재현되지 못하 였다. $\mathrm{F}$ 는 본 문항을 삭제하여 설문지의 형식적 등가성이 완전 히 결여되었다.

문항 7: When I am at the dinner table with several people, and am trying to have a conversation with one person, understanding speech is difficult

$\mathrm{A}$ 는 "여러 사람과 식사를 하면서 그중 한 사람과 이야기할 
때 대화를 이해하기 어렵다." B는 "나는 여러 사람과의 저녁 식 사 중 한 사람과 이야기를 할 때 어려움이 있습니다." C는 "여러 사람과 식사 중, 한 사람과 대화할 때 그 사람의 말을 이해하기 가 어렵다." D와 $\mathrm{E}$ 는 "여러 사람과 저녁 식사를 할 때, 한 사람 과 대화를 하고 있는 데 대화 음을 이해하기가 어렵다.”로 번역 하였다. $\mathrm{A}$ 와 $\mathrm{C}$ 는 형식적과 역동적 등가성을 확보하였다. $\mathrm{B}$ 는 원본의 'understanding speech'를 생략하고 번역하여 형식적 등가성을 확보하지 못하였다. $\mathrm{D}$ 와 $\mathrm{E}$ 는 적절하지 않은 단어를 선택하였는데 'speech'를 '대화 음'으로 번역하여 대화 내용이 아닌 일반적인 소리로 의미가 왜곡되어 형식적 및 역동적 등가 성을 모두 충족하지 못하였다. $\mathrm{F}$ 는 본 문항을 삭제하여 설문지 의 형식적 등가성이 완전히 결여되었다.

\section{문항 8: Traffic noises are too loud}

$\mathrm{A}$ 는 "거리의 교통 소음이 너무 시끄럽다." $\mathrm{B}$ 는 "거리의 교통 소음이 너무 시끄럽습니다." C는 "거리에서 자동차 소음이 너 무 크게 들린다." D와 E는 “교통 소음이 너무 크다.”로 번역하였 다. A, B, C는 '거리'라는 원본에 없는 단어가 추가되어 형식적 등가성이 확보하지 못하였지만, $\mathrm{D}$ 와 $\mathrm{E}$ 는 형식적 및 역동적 등 가성이 확보된 것으로 나타났다. $\mathrm{F}$ 는 본 문항을 삭제하여 설문 지의 형식적 등가성이 완전히 결여되었다.

문항 9: When I am talking with someone across a large empty room, I understand the words

$\mathrm{A}$ 는 "큰 방을 가로질러 누군가와 대화할 때 잘 이해한다." B 는 "나는 커다란 빈 방 안에서 건너편 누군가와 이야기를 할 때 그 말을 이해할 수 있습니다." C는 "큰 방이나 넓은 거실에서 멀 리 떨어져 있는 사람과 대화할 때 말을 이해할 수 있다.” D와 E 는 "커다란 빈 방을 가로질러 다른 사람과 이야기할 때 말을 이 해한다.”로 번역하였다. D와 E는 형식적 등가성이 확보되었고, $\mathrm{B}, \mathrm{D}, \mathrm{E}$ 는 맥락상 원본의 의미를 재현하고 있어 역동적 등가성 을 확보하였다. A와 C는 'large empty room'을 '큰 방' 혹은 '큰 방이나 넓은 거실'로 번역하여 '넓고 텅 빈 방'을 의미하는 내용 이 왜곡되었으며, C에서는 'someone'을 '멀리 떨어져 있는 사람' 으로 원본에 없는 내용이 추가되어 형식적 및 역동적 등가성을 모두 충족시키지 못하였다. F는 본 문항을 삭제하여 설문지의 형식적 등가성이 완전히 결여되었다.

문항 10: When I am in a small office, interviewing or answering questions, I have difficulty following the conversation

$\mathrm{A}$ 는 "조그만 사무실 안에서 질문을 받고 대답해야 하는 경 우 대화를 잘 이해하지 못한다." $\mathrm{B}$ 는 "나는 작은 사무실 안에
서 면접을 보거나 질문에 대답할 때 대화를 이해하는 것이 어 렵습니다." C는 "조용한 사무실에서 질문하는 내용을 알아듣는 데 어려움이 있다." D와 $\mathrm{E}$ 는 "작은 사무실에서 인터뷰를 하거나 질문에 답할 때 대화를 따라가기가 어렵다."로 번역하였다. D와 $\mathrm{E}$ 는 형식적 등가성이 확보되었고, $\mathrm{B}, \mathrm{D}, \mathrm{E}$ 는 비교적 역동적 등가 성을 확보하였다. $\mathrm{A}$ 는 'interviewing or answering questions'를 '질문을 받고 대답해야 하는 경우”로 번역하였고, C는 'interviewing'의 번역을 생략하였으며, $\mathrm{F}$ 는 본 문항을 삭제하여 설 문지의 형식적 등가성이 완전히 결여되었다.

문항 11: When I am in a theater watching a movie or play, and the people around me are whispering and rustling paper wrappers, I can still make out the dialogue $\mathrm{A}$ 는 "극장에서 주위 사람들이 속삭이는 소리를 내도 영화 대사를 잘 알아듣는다." $\mathrm{B}$ 는 "나는 극장에서 영화나 연극을 볼 때 주변에서 속삭이거나 바스락거리는 소리가 나도 대사를 이 해할 수 있습니다." C는 "TV 드라마를 보고 있을 때, 주변 사 람들이 소곤거리거나 종이를 부스럭거려도 대사를 이해할 수 있다." D는 “극장에서 영화를 보거나 활동을 할 때, 주변 사람 이 소곤거리고 신문지로 바스락거려도 나는 계속 대화를 할 수 있다." E는 "영화관에서 영화를 보거나 활동을 할 때, 주변 사 람이 소곤거리고 신문지로 바스락거려도 나는 계속 대화를 할 수 있다.”로 번역하였다. 모든 번역본에서 단어가 일치하지 못하 고 어구 일부가 삭제되어 형식적 등가성이 확보되지 못하였고, $\mathrm{B}$ 만이 역동적 등가성을 어느 정도 확보하였다. 그 외의 번역본 에서는 원본과는 다른 듣기 환경으로 내용이 바뀌어 있었다. 예를 들면 'in a theater watching a movie or play'를 A는 '극 장, C는 'TV 드라마'로 번역하였고, '연극'이라는 'play'를 D와 E 는 '활동’으로 번역하여 문맥상 어색하고 자연스럽지 않았고 원 본의 의미를 왜곡하였다. $\mathrm{F}$ 는 본 문항을 삭제하여 설문지의 형 식적 등가성이 완전히 결여되었다.

문항 12: When I am having a quiet conversation with a friend, I have difficulty understanding

$\mathrm{A}$ 는 "친구 한 사람과 조용히 대화할 경우 잘 알아듣지 못한 다." B는 "나는 친구와 조용히 이야기를 할 때 알아듣기가 어렵 습니다." C는 "친구와 조용히 대화를 나눌 때 말을 이해하는 데 어려움이 있다." D와 E는 "친구와 조용한 대화를 나눌 때, 말을 이해하기가 어렵다."로 번역하였다. 간단한 문장이므로 모 든 번역본에서 비교적 형식적 및 역동적 등가성을 확보하였다. $\mathrm{F}$ 는 본 문항을 삭제하여 설문지의 형식적 등가성이 완전히 결 여되었다. 
문항 13: The sounds of running water, such as a toilet or shower, are uncomfortably loud

$\mathrm{A}$ 는 “욕실이나 변기의 물소리가 너무 시끄럽다." $\mathrm{B}$ 는 “샤워기 또는 변기의 물을 내릴 때 나는 소리는 불쾌하게 시끄럽습니 다." C는 "화장실 물 내리는 소리 또는 샤워할 때 물 떨어지는 소리가 불쾌할 정도로 시끄럽다." D와 $\mathrm{E}$ 는 "화장실이나 샤워실 의 물소리는 불쾌할 만큼 크다.”로 번역하였다. 영어의 표현적 특성이 한국어와 매우 다른 문장이어서 모든 번역본이 형식적 등가성을 확보하지 못하였으나, C, D, E는 자연스럽게 원본의 의미를 전달하고 있어 어느 정도 역동적 등가성이 있는 것으로 생각된다. $\mathrm{A}$ 는 'running water'라는 원본의 내용이 생략되었고 $\mathrm{B}$ 는 '샤워기 또는 변기의 물을 내릴 때 나는 소리'라는 표현으 로 원본의 'running water'가 '물이 흐르는 소리'인지 정확하게 표현되지 않아 원본 내용을 제대로 재현하지 못하였다. $\mathrm{F}$ 는 본 문항을 삭제하여 설문지의 형식적 등가성이 완전히 결여되었다.

문항 14: When a speaker is addressing a small group, and everyone is listening quietly, I have to strain to understand

$\mathrm{A}$ 는 "한 사람이 여러 사람을 차례로 소개할 때 주위가 조용 하더라도 긴장해야 알아듣는다." $\mathrm{B}$ 는 "누군가 작은 모임에서 말을 하고 청중이 조용히 듣고 있을 때에도 나는 내용을 알아 들으려면 애써야 합니다." C는 "소모임에서 한 사람이 강의를 할 때 다른 사람들이 조용히 경청하는 동안, 강의를 알아듣기 위해서 긴장해야 한다." $\mathrm{D}$ 와 $\mathrm{E}$ 는 "누군가 작은 모임에서 연설 을 할 때, 모두가 조용히 경청하는 동안 나는 이해하려고 긴장 해야 한다."로 번역하였다. 모든 번역본에서 형식적 및 역동적 등가성을 확보하지 못하였다. A는 "when a speaker is addressing a small group'을 '한 사람이 여러 사람을 차례로 소개할 때' 로 번역하였고, B와 C는 'everyone'을 '청중이', '다른 사람들이' 로 각각 번역하여 원본의 의미가 재현되지 않았다. 또한 $\mathrm{A}, \mathrm{B}$, C, D, E에서 'addressing'을 '소개', '말', '강의', '연설'로 다양하게 번역하였다. $\mathrm{F}$ 는 본 문항을 삭제하여 설문지의 형식적 등가성 이 완전히 결여되었다.

문항 15: When I'm in a quiet conversation with my doctor in an examination room, it is hard to follow the conversation

$\mathrm{A}$ 는 "의사 선생님과 진찰실에서 조용히 대화할 때 잘 알아듣 지 못한다." $\mathrm{B}$ 는 "나는 진찰실에서 담당 의사와 조용히 대화할 때 알아듣기가 어렵습니다." $\mathrm{C}$ 는 "진료실에서 의사와 나누는 조용한 대화를 알아듣기가 어렵다." $\mathrm{D}$ 와 $\mathrm{E}$ 는 "진찰실에서 의사 와 조용한 대화를 하는 동안 대화를 따라가기가 어렵다.”로 번 역하였다. 원본에서 의미하는 'my doctor'는 주치의라는 의미로
여러 번 함께 의사소통한 경험이 있는 의사라는 의미지만, 모 든 번역본에서 '의사 선생님' '담당 의사', '의사로 번역하여 어 떠한 번역본도 원본의 의미를 재현하고 있지 않아 형식적 및 역 동적 등가성을 확보하지 못하였다. $\mathrm{F}$ 는 본 문항을 삭제하여 설 문지의 형식적 등가성이 완전히 결여되었다.

\section{문항 16: I can understand conversations even when} several people are talking

$\mathrm{A}$ 는 "여러 사람이 말할 때에도 대화를 이해한다." $\mathrm{B}$ 는 "나는 여러 사람이 이야기를 하고 있을 때에도 그 대화들을 알아들 을 수 있습니다." C는 "여러 사람이 이야기할 때 그 대화를 알 아들을 수 있다." D와 E는 "여러 사람이 말하고 있을 때 대화 를 이해할 수 있다.”로 번역하였다. A, D, E는 형식적 등가성을 확보하였고, $\mathrm{A}, \mathrm{B}, \mathrm{C}, \mathrm{D}, \mathrm{E}$ 는 원본에서 의도했던 내용을 자연 스럽게 번역하여 역동적 등가성을 충족하였다. $\mathrm{F}$ 는 본 문항을 삭제하여 설문지의 형식적 등가성이 완전히 결여되었다.

\section{문항 17: The sounds of construction works are} uncomfortably loud

$\mathrm{A}$ 는 "공사장 소음은 너무 시끄럽다.” $\mathrm{B}$ 는 "공사장 소음은 불 쾌하게 시끄럽습니다." C는 "공사장의 소음이 불편할 정도로 크 다." $\mathrm{D}$ 와 $\mathrm{E}$ 는 "건설 현장의 소리는 불쾌하도록 크다.”로 번역하 였다. D와 E는 형식적 등가성을 확보하였고, $\mathrm{C}, \mathrm{D}, \mathrm{E}$ 는 자연스 럽게 내용을 전달하여 역동적 등가성을 충족하였다. A는 'uncomfortably'를 '너무로 왜곡된 번역을 하였으며, B는 '불쾌하 게”로 번역하였는데 이 표현은 ‘불쾌할 정도로’가 문맥상 자연스 러운 번역이므로 역동적 등가성을 확보한 것으로 판단하기 어 려웠다. $\mathrm{F}$ 는 본 문항을 삭제하여 설문지의 형식적 등가성이 완 전히 결여되었다.

문항 18: It's hard for me to understand what is being said at lectures or church services

$\mathrm{A}$ 는 "강의나 교회 설교를 들을 때 뭐라고 했는지 못 알아듣 는다." B는 "나는 강의 또는 예배에서 하는 말을 알아듣기 어렵 습니다." C는 "강의실이나 교회에서 강의 또는 설교를 알아듣 기 어렵다." $\mathrm{D}$ 는 "강의나 교회 설교를 이해하기가 어렵다." $\mathrm{E}$ 는 "강의 시간이나 교회에서 설교를 이해하기가 어렵다."로 번역하 였다. 본 문항은 종교의 문화적 특성과 영어와 한국어의 표현 이 달라 모든 번역본이 형식적 및 역동적 등가성을 확보하지 못 하였다. 왜냐하면 본 문항은 "강의나 교회 예배 시 강의 내용이 나 설교를 이해하기 어렵다.”가 비교적 문맥상 자연스러운 표현 으로 보이는데 이러한 자연스러운 표현은 여섯 가지 번역본 중 에서는 존재하지 않았다. $\mathrm{F}$ 는 본 문항을 삭제하여 설문지의 형 
식적 등가성이 완전히 결여되었다.

문항 19: I can communicate with others when we are in a crowd

$\mathrm{A}$ 는 "혼잡한 곳에서 다른 사람들과 언어소통이 가능하다." $\mathrm{B}$ 는 "나는 군중 속에 있을 때 다른 사람들과 대화를 나눌 수 있습니다." C는 "사람이 많은 곳에서도 다른 사람과 의사소통 이 가능하다." D와 E는 "군중 속에서 다른 사람들과 대화할 수 있다."로 번역하였다. 간단한 문장이므로 모든 번역본에서 어느 정도 형식적 등가성이 확보되었고, $\mathrm{C}$ 는 자연스럽게 의미가 전 달되어 역동적 등가성도 확보한 것으로 나타났다. $\mathrm{F}$ 는 본 문항 을 삭제하여 설문지의 형식적 등가성이 완전히 결여되었다.

문항 20: The sound of a fire engine siren close by is so loud that I need to cover my ears

$\mathrm{A}$ 는 "근처에서 소방차 사이렌 소리가 나면 귀를 막게 된다." $\mathrm{B}$ 는 "가까이에서 소방차 사이렌 소리가 나면 너무 시끄러워서 귀를 막아야 합니다." C는 "사이렌 소리 또는 자동차 경적음 소 리가 너무 시끄러워서 귀를 막아야 한다." $\mathrm{D}$ 는 "소방차 사이렌 소리가 옆으로 지나가면 나는 귀를 막아야 한다." $\mathrm{E}$ 는 "소방차 가 옆으로 지나가면 사이렌 소리에 나는 귀를 막아야 한다.”로 번역하였다. $\mathrm{B}$ 는 문법과 단어상 일치를 보여 형식적 및 역동적 등가성을 확보하였다. 그 외의 번역본들은 원본의 단어를 삭제 하거나 불필요한 단어를 추가하였는데, 예를 들면 $\mathrm{C}$ 는 '자동차 경적음 소리'를 추가하였고, A, D, E는 'so loud'에 대한 내용을 번역하지 않았다. F는 본 문항을 삭제하여 설문지의 형식적 등 가성이 완전히 결여되었다.

\section{문항 21: I can follow the word of a sermon when} listening to a religious service

$\mathrm{A}$ 는 "교회나 절 혹은 다른 집회에서 설교(강의) 내용을 제대 로 이해한다." $\mathrm{B}$ 는 "나는 종교 의식에서 설교나 강의를 이해할 수 있습니다." $\mathrm{C}$ 는 "성당이나 절, 교회에서 설교(강의)를 알아 들을 수 있다.” $\mathrm{D}$ 와 $\mathrm{E}$ 는 “종교 집회에서 설교자의 말을 따라갈 수 있다." F는 "예배, 강론 또는 설법 시 그 내용을 이해하기 어 렵다."로 번역하였다. 문화적으로 종교에 차이가 있어 모든 번역 본이 형식적 및 역동적 등가성을 확보하지 못하였다. 예를 들어 $\mathrm{A}$ 와 C는 'religious service'를 '절, 교회, 성당' 등 원본에 없는 단어를 추가하였고 $\mathrm{B}$ 는 '강의'라는 표현이 새롭게 추가되었으 며 $\mathrm{D}$ 와 $\mathrm{E}$ 에서는 'sermon'을 '설교자'로 번역하여 등가성을 충족 하지 못하였다.
문항 22: The sound of screeching tires is uncomfortably loud

$\mathrm{A}$ 는 "차의 타이어 긁히는 소리는 너무 시끄럽다." $\mathrm{B}$ 는 "급정 거할 때 나는 타이어 소리는 불쾌하게 시끄럽습니다." C는 "끽 ' 하는 타이어 미끄러지는 소리가 불쾌하게 들린다.” $\mathrm{D}$ 와 $\mathrm{E}$ 는 "찢어지는 듯한 타이어 소리는 불쾌하게 들린다."로 번역하였다. 모든 번역본에서 "the sound of screeching tires'는 "브레이크 밟을 때 나는 끽 소리'를 의미하는데, 이를 적절히 형식적으로 번역하기 어려운 면이 있어 형식적 및 역동적 등가성을 확보하 지 못하였다. 예를 들어 B와 C는 '급정거할 때' "끽 하는이라 는 불필요한 단어를 추가하였으며, A, D, E는 'uncomfortably' 를 '너무' 혹은 '불쾌하게'로 번역하여 등가성이 확보되지 못하 였다. $\mathrm{F}$ 는 본 문항을 삭제하여 설문지의 형식적 등가성이 완전 히 결여되었다.

문항 23: I have to ask people to repeat themselves in one-on-one conversation in a quiet room

$\mathrm{A}$ 는 "조용한 방에서 다른 두 사람이 대화하는 것을 들을 때 다시 이야기해 달라고 부탁한다." $\mathrm{B}$ 는 "나는 조용한 방에서 일 대일로 대화를 나눌 때 사람들에게 다시 말해달라고 부탁해야 합니다." C는 "조용한 방에서 1:1로 대화할 때 상대방에게 되물 어야 한다." D와 $\mathrm{E}$ 는 "조용한 방에서 일대일로 대화를 할 때에 나는 상대방이 말을 반복하여 줄 것을 요청한다." $\mathrm{F}$ 는 "조용한 방에서 한 사람과 대화할 때 자주 되물어야 한다.”로 번역하였 다. $\mathrm{B}$ 는 형식적 및 역동적 등가성을 확보하였으며, $\mathrm{D}, \mathrm{E}$ 는 의미 전달 면에서 어느 정도 역동적 등가성을 가졌다. $\mathrm{A}$ 는 "in oneon-one conversation in a quiet room'을 '조용한 방에서 다른 두 사람이 대화하는 것을 들을 때', C는 'I have to ask people to repeat themselves'를 '상대방에게 되물어야 한다로 번역을 하여 등가성을 확보하지 못하였다. F는 '자주라는 원본에 없는 단어를 첨가하고 누구에게 물어야 하는지를 생략하여 형식적 및 역동적 등가성을 확보하지 못하였다.

\section{문항 24: I have trouble understanding others when an} air conditioner or fan is on

$\mathrm{A}$ 는 "선풍기나 에어콘을 켜 놓으면 대화하기가 곤란하다." B 는 "나는 에어컨이나 환풍기가 켜져 있을 때 다른 사람들의 대 화를 알아듣기가 어렵습니다." C는 "선풍기나 에어컨이 켜져 있 을 때 다른 사람의 말을 이해하기가 어렵다." D와 $\mathrm{E}$ 는 "에어컨 이나 선풍기가 작동할 때 다른 사람의 말을 이해하기가 어렵 다.”로 번역하였다. 영어에서 'fan'은 '천장에 돌아가는 팬', '선풍 기', '환풍기' 등 여러 가지 의미를 함축하고 있어 번역본도 '선풍 기'나 ‘환풍기' 등으로 다양하게 번역되었다. 따라서 형식적 등 
가성은 어떠한 번역본도 충족될 수 없었으나, 역동적 등가성은 $\mathrm{C}, \mathrm{D}, \mathrm{E}$ 가 의미 전달 면에서 어느 정도 확보한 것으로 나타났다. $\mathrm{F}$ 는 본 문항을 삭제하여 설문지의 형식적 등가성이 완전히 결 여되었다.

6개 번역본에 대한 등가성 분석 결과를 요약해 보면, 모든 문 항에 등가성이 확보된 번역본은 없는 것을 확인할 수 있었다. 번역본들이 등가성이 확보되었을 경우는 2점, 어느 정도 등가 성이 확보되었을 경우는 1점, 등가성이 완전히 결여되었을 경우 는 0 점을 주었다. 점수화하였을 때 6개 번역본 중 $\mathrm{D}$ 와 $\mathrm{E}$ 가 11점 으로 가장 형식적 등가성이 확보된 편에 속했으며 그 다음은 9 점을 확보한 $\mathrm{B}$ 로 나타났다. 반면에 역동적 등가성은 $\mathrm{B}$ 가 21점, $\mathrm{D}$ 와 E가 모두 20점으로 나타났다(Table 4). 그러나 만점이 48점 임을 고려할 때 어떠한 번역본이든 절반의 등가성도 확보하지 못한 것으로 나타났다.

\section{번역본별 통계적 검증 분석}

번역된 설문지의 각 문항이 적절하게 이루어져 있는지 확인 하기 위하여 통계적 분석 과정이 실시되어야 하는데 6개 번역 본 중 B와 F만이 Cronbach's $\alpha$ 를 통하여 신뢰도를 평가하였 다. $\mathrm{B}$ 의 항목별 Cronbach's $\alpha$ 값은 $\mathrm{EC}$ 는 $0.86, \mathrm{AV}$ 는 $0.85, \mathrm{RV}$ 는 $0.65, \mathrm{BN}$ 은 0.58 로 0.7 보다 낮은 항목이 두 개였으며, $\mathrm{F}$ 의 항 목별 Cronbach's $\alpha$ 값은 EC는 0.78, BN은 0.79, RV는 0.81, AV 는 0.75, LC는 0.79로 모두 0.7을 넘는 신뢰도를 보였다(Kim et al., 2016; Lim et al., 2017). 원본 APHAB의 항목별 Cronbach's $\alpha$ 값은 $\mathrm{EC}$ 는 $0.79, \mathrm{RV}$ 는 $0.78, \mathrm{BN}$ 은 $0.80, \mathrm{AV}$ 는 0.82 였다(Cox \& Alexander, 1995). 번역본 $\mathrm{B}$ 는 RV와 $\mathrm{BN}$ 항목에서 비교적 낮은 신뢰도를 보였으며, 번역본 $\mathrm{F}$ 는 등가성은 결여되었으나 설 문지 그 자체는 신뢰도가 확보된 것으로 분석되었다.

타당도 검증으로는 번역본 $\mathrm{B}$ 와 $\mathrm{F}$ 에 요인 분석을 시행하였다. 총 요인의 수는 $\mathrm{B}$ 는 3 개, $\mathrm{F}$ 는 4 개였고 제 1 요인은 $\mathrm{B}$ 에서 $\mathrm{EC}$,

Table 4. Analysis of formal and dynamic equivalences of the Korean version of abbreviated profile of hearing aid benefits

\begin{tabular}{|c|c|c|c|c|c|c|c|c|c|c|c|c|}
\hline \multirow{2}{*}{ Items } & \multicolumn{6}{|c|}{ Formal equivalence } & \multicolumn{6}{|c|}{ Dynamic equivalence } \\
\hline & A & B & $\mathrm{C}$ & $\mathrm{D}$ & $\mathrm{E}$ & $\mathrm{F}$ & A & $\mathrm{B}$ & $\mathrm{C}$ & $\mathrm{D}$ & $\mathrm{E}$ & $\mathrm{F}$ \\
\hline 1 & $\mathrm{X}$ & $\mathrm{X}$ & $\mathrm{X}$ & $\mathrm{X}$ & $\mathrm{X}$ & $\mathrm{X}$ & $\mathrm{X}$ & $\mathrm{X}$ & $\mathrm{X}$ & O & $\bigcirc$ & $\mathrm{X}$ \\
\hline 2 & $\mathrm{X}$ & $\mathrm{X}$ & $\triangle$ & $\bigcirc$ & $\bigcirc$ & $\mathrm{X}$ & $\mathrm{X}$ & $\mathrm{X}$ & $\bigcirc$ & $\mathrm{X}$ & $\mathrm{X}$ & $\mathrm{X}$ \\
\hline 3 & $\mathrm{X}$ & $\bigcirc$ & $\mathrm{X}$ & $\mathrm{X}$ & $\mathrm{X}$ & $\mathrm{X}$ & $\bigcirc$ & $\bigcirc$ & $\mathrm{X}$ & $\triangle$ & $\triangle$ & $\mathrm{X}$ \\
\hline 4 & $\mathrm{X}$ & $\mathrm{X}$ & $\bigcirc$ & $\mathrm{X}$ & $\mathrm{X}$ & $\mathrm{X}$ & $\mathrm{X}$ & $\triangle$ & $\bigcirc$ & $\mathrm{X}$ & $\mathrm{X}$ & $\mathrm{X}$ \\
\hline 5 & $\mathrm{X}$ & O & $\mathrm{X}$ & $\mathrm{X}$ & $\mathrm{X}$ & $\mathrm{X}$ & $\mathrm{X}$ & $\bigcirc$ & $\mathrm{X}$ & $\mathrm{X}$ & $\mathrm{X}$ & $\mathrm{X}$ \\
\hline 6 & $\mathrm{X}$ & $\mathrm{X}$ & $\mathrm{X}$ & $\mathrm{X}$ & $\mathrm{X}$ & $\mathrm{X}$ & $\mathrm{X}$ & 0 & $\mathrm{X}$ & 0 & $\bigcirc$ & $\mathrm{X}$ \\
\hline 7 & $\triangle$ & $\mathrm{X}$ & $\triangle$ & $\mathrm{X}$ & $\mathrm{X}$ & $\mathrm{X}$ & $\triangle$ & $\mathrm{X}$ & 0 & $\mathrm{X}$ & $\mathrm{X}$ & $\mathrm{X}$ \\
\hline 8 & $\mathrm{X}$ & $\mathrm{X}$ & $\mathrm{X}$ & 0 & 0 & $\mathrm{X}$ & $\mathrm{X}$ & $\mathrm{X}$ & $\mathrm{X}$ & 0 & 0 & $\mathrm{X}$ \\
\hline 9 & $\mathrm{X}$ & $X$ & $\mathrm{X}$ & $\triangle$ & $\triangle$ & $\mathrm{X}$ & $\mathrm{X}$ & $\triangle$ & $\mathrm{X}$ & $\triangle$ & $\triangle$ & $\mathrm{X}$ \\
\hline 10 & $\mathrm{X}$ & $X$ & $\mathrm{X}$ & $\triangle$ & $\triangle$ & $\mathrm{X}$ & $\mathrm{X}$ & 0 & $\mathrm{X}$ & $\triangle$ & $\triangle$ & $\mathrm{X}$ \\
\hline 11 & $X$ & $\mathrm{X}$ & $\mathrm{X}$ & $X$ & $\mathrm{X}$ & $\mathrm{X}$ & $\mathrm{X}$ & $\triangle$ & $X$ & $\mathrm{X}$ & $\mathrm{X}$ & $\mathrm{X}$ \\
\hline 12 & $\triangle$ & $\triangle$ & $\triangle$ & $\triangle$ & $\triangle$ & $\mathrm{X}$ & $\bigcirc$ & 0 & 0 & $\bigcirc$ & $\bigcirc$ & $\mathrm{X}$ \\
\hline 13 & $\mathrm{X}$ & $\mathrm{X}$ & $\mathrm{X}$ & $\mathrm{X}$ & $\mathrm{X}$ & $\mathrm{X}$ & $\mathrm{X}$ & $\mathrm{X}$ & $\mathrm{X}$ & $\triangle$ & $\triangle$ & $\mathrm{X}$ \\
\hline 14 & $\mathrm{X}$ & $X$ & $X$ & $\mathrm{X}$ & $X$ & $\mathrm{X}$ & $\mathrm{X}$ & $\mathrm{X}$ & $X$ & $\mathrm{X}$ & $\mathrm{X}$ & $\mathrm{X}$ \\
\hline 15 & $\mathrm{X}$ & $\mathrm{X}$ & $\mathrm{X}$ & $\mathrm{X}$ & $\mathrm{X}$ & $\mathrm{X}$ & $\mathrm{X}$ & $\mathrm{X}$ & $\mathrm{X}$ & $\mathrm{X}$ & $\mathrm{X}$ & $\mathrm{X}$ \\
\hline 16 & 0 & $\mathrm{X}$ & $\mathrm{X}$ & $\triangle$ & $\triangle$ & $\mathrm{X}$ & 0 & 0 & 0 & 0 & 0 & $\mathrm{X}$ \\
\hline 17 & $\mathrm{X}$ & $\mathrm{X}$ & $\mathrm{X}$ & $\bigcirc$ & 0 & $\mathrm{X}$ & $\mathrm{X}$ & $\mathrm{X}$ & 0 & 0 & $\bigcirc$ & $\mathrm{X}$ \\
\hline 18 & $\mathrm{X}$ & $\mathrm{X}$ & $X$ & $\mathrm{X}$ & $X$ & $\mathrm{X}$ & $\mathrm{X}$ & $\mathrm{X}$ & $\mathrm{X}$ & $\mathrm{X}$ & $\mathrm{X}$ & $\mathrm{X}$ \\
\hline 19 & $\triangle$ & $\triangle$ & $\triangle$ & $\triangle$ & $\triangle$ & $\mathrm{X}$ & 0 & 0 & 0 & 0 & 0 & $\mathrm{X}$ \\
\hline 20 & $\mathrm{X}$ & 0 & $X$ & $X$ & $\mathrm{X}$ & $\mathrm{X}$ & $\mathrm{X}$ & 0 & $\mathrm{X}$ & $\mathrm{X}$ & $\mathrm{X}$ & $\mathrm{X}$ \\
\hline 21 & $\mathrm{X}$ & $\mathrm{X}$ & $\mathrm{X}$ & $\mathrm{X}$ & $X$ & $\mathrm{X}$ & $\mathrm{X}$ & $\mathrm{X}$ & $X$ & $\mathrm{X}$ & $\mathrm{X}$ & $\mathrm{X}$ \\
\hline 22 & $\mathrm{X}$ & $\mathrm{X}$ & $X$ & $\mathrm{X}$ & $\mathrm{X}$ & $\mathrm{X}$ & $\mathrm{X}$ & $\mathrm{X}$ & $\mathrm{X}$ & $\mathrm{X}$ & $\mathrm{X}$ & $\mathrm{X}$ \\
\hline 23 & $\mathrm{X}$ & $\triangle$ & $X$ & $\mathrm{X}$ & $X$ & $\mathrm{X}$ & $\mathrm{X}$ & 0 & $X$ & $\triangle$ & $\triangle$ & $\mathrm{X}$ \\
\hline 24 & $\mathrm{X}$ & $\mathrm{X}$ & $\mathrm{X}$ & $\mathrm{X}$ & $\mathrm{X}$ & $\mathrm{X}$ & $\mathrm{X}$ & $\mathrm{X}$ & $\triangle$ & $\triangle$ & $\triangle$ & $\mathrm{X}$ \\
\hline 0 & 1 & 3 & 1 & 3 & 3 & 0 & 4 & 9 & 7 & 7 & 7 & 0 \\
\hline$\triangle$ & 3 & 3 & 4 & 5 & 5 & 0 & 1 & 3 & 1 & 6 & 6 & 0 \\
\hline$X$ & 20 & 18 & 19 & 16 & 16 & 24 & 19 & 12 & 16 & 11 & 11 & 24 \\
\hline Score & 5 & 9 & 6 & 11 & 11 & 0 & 9 & 21 & 15 & 20 & 20 & 0 \\
\hline
\end{tabular}


$\mathrm{BN}, \mathrm{RV}$ 항목의 총 12 문항으로 구성되어 '일상생활에서의 의사 소통, $\mathrm{F}$ 에서는 $\mathrm{BN}, \mathrm{RV}$ 항목의 총 8 문항으로 구성되어 ‘의사소 통이 어려운 상황'으로 명명하였다. 제2요인은 $\mathrm{B}$ 에서 $\mathrm{AV}$ 항목 의 총 6 문항으로 구성되어 '큰 소리에 대한 불쾌감', F에서는 LC 항목으로만 이루어진 총 4문항으로 '방향성’으로 명명하였다. 제 3 요인은 $\mathrm{B}$ 에서 $\mathrm{BN}$ 과 RV 항목의 총 6 문항으로 '소음과 반향 음 상황에서의 의사소통, F에서는 EC 항목으로만 이루어진 총 4 문항으로 '쉬운 의사소통'으로 명명하였다. 마지막으로 B에서 제4요인은 AV 항목으로만 이루어진 총 4문항으로 '크고 날카로 운 음으로 명명하였다(Kim et al., 2016; Lim et al., 2017).

\section{CONCLUSIONS}

본 연구는 Cox \& Alexander(1995)의 APHAB을 국내에서 번역하여 사용 중인 6 개 번역본들에 대하여 등가성 확보 여부 와 통계적 검증을 확인하고 번역본으로서 활용도를 밝히고자 하였다. 본 연구에서 검토한 6 개의 모든 번역본은 형식적 및 역 동적 등가성이 절반 이하 정도의 수준으로 나타났다. 또한 통계 적으로 검증된 번역본도 두 개뿐이어서 $\mathrm{APHAB}$ 원본을 재현 하여 번역본으로 사용하는 데 한계점을 확인하였다. 더욱이 번 역본 $\mathrm{F}$ 는 원본 $\mathrm{APHAB}$ 의 24 개 문항 중 18 개 문항을 삭제하고 6 개 문항을 국내 정서를 고려하여 재구성한 뒤 1 개의 방향성 (LC) 항목을 추가하고 14 개의 새로운 문항을 추가하여 총 20 문항으로 $\mathrm{APHAB}$ 과는 총 문항 수에도 차이가 있다(Kim et al., 2016). 따라서 원본과 비교하기에 무리가 있어 $\mathrm{APHAB}$ 의 번역본으로 보기가 어려웠다. 차라리 $\mathrm{APHAB}$ 을 참조한 새로운 설문지 개발로 저자가 재정리하여 설문지 제목도 K-PHAB이 아닌 다른 것으로 소개하는 편이 좋을 것으로 생각된다. 특히 $\mathrm{KS}$ 문서에 $\mathrm{APHAB}$ 의 국내본의 대표로 K-PHAB으로 명명되어 소 개된 내역은 정정이 필요한 부분이다. 또한 번역본별 문항 분석 에서 문항 $1,3,4,6,11,18,20$ 은 6 개 번역본 모두 각기 다르게 번역되어 있는 차이가 확연한 것으로 나타났다. 원본과 번역본 에서 나타나는 이러한 차이는 문화와 정서 차이에서 기인한 것 으로 형식적 및 문화적 등가성을 침해한 것으로 분석된다.

이와 같이 본 연구에서 검토한 $\mathrm{APHAB}$ 뿐 아니라 다른 설문 지에서도 번역본의 한계점을 보였다. 보청기 착용 시 만족도를 평가하는 설문지인 SADL 번역본(Kim et al., 2018)은 원 논문 과 비교할 때 4개 항목 중 '개인적 이미지' 항목의 평균 점수가 매우 낮았다. 이는 보청기 착용에 대한 국내의 정서는 외국보다 부정적이기 때문이라고 하였으며, 번역된 문항들 중 해석이 불 명확한 경우도 존재했다(Lee et al., 2004). 또한 난청에 대한 태 도를 평가하는 ALHQ (Jo et al., 2011)는 5개 항목 중 하나의 항목에서만 0.6 이상의 Cronbach's $\alpha$ 값을 보여 신뢰도 있는
설문지로 보기 어려웠는데 이는 번역 과정에서 심리적 부분에 대한 번역이 어려웠던 점이 원인인 것으로 생각된다.

외국의 설문지를 국내에서 번역하여 사용할 때 언어 간 구조 가 달라 원본에서는 인칭이나 지시 대명사를 사용하지만 번역 본에서는 생략되어 원본의 내용을 제대로 표현 못할 수 있고, 문화적으로 종교나 관습의 차이로 번역의 한계가 나타난다. 이 러한 요소는 설문 응답 시 방해 요인이 되어 결과에 문제가 될 수 있으므로 현재 여러 분야에서 국내 정서와 문화를 반영하고 한국어 특성이 반영된 설문지를 개발하였다. 예를 들어 언어치 료학에서는 국내 개발본을 이용한 평가 및 설문지가 널리 사용 되고 있는데, 취학 전 아동의 수용언어 및 표현언어능력을 측정 하는 preschool receptive-expressive language scale (Kim, 2000)과 영유아의 언어 발달 정도를 검사하는 sequenced language scale for infants (Kim, 2002) 등은 한국어로 개발되어 한국 아동의 언어능력을 평가하는 데 사용하고 있다. 청각학도 의사소통 영역을 다루는 학문 중 하나로 언어치료학과 같이 문 화 정서적 차이로 번역본에 제한이 있을 수 있다. 또한 교육 분 야에서도 문화적 특성과 정서적 내용을 질문하는 설문지를 한 국어로 개발하여 사용하고 있는데, achievement emotions questionnaire-Korean middle school science (Jeon, 2014)는 정서가 문화적 배경에 따라 결정되므로 Pekrun et al.(2011)이 개발한 achievement emotion questionnaire (AEQ)를 바탕으 로 한국 학생들만 경험하는 고유한 학습 정서와 과학 영역에 대한 한국 중학생의 성취 정서를 평가할 수 있는 설문 문항을 개발하였다. 의학 분야에서는 비만과 관련한 삶의 질을 평가하 는 설문지인 Korean version of obesity-related quality of life scale (Park et al., 2003)을 개발하여 사용하고 있는데 이는 한 국인과 서구인의 비만 정도와 양상이 달라 신체적 차이를 고려 하여 impact of weight on quality of life (Kolotkin et al., 1997)와 impact of weight on quality of life-lite (Kolotkin et al., 2001) 등 외국의 설문지를 바탕으로 국내 정서에 맞는 설문 지로 개발하였다. 예를 들어 설문 문항에는 '쪼그리고 앉아서 일하기 힘들다.와 같이 한국인의 문화를 반영하는 특이적 문 항을 포함하여 한국 비만 환자의 평가에 활용되고 있다.

이처럼 언어와 정서 및 문화적 차이는 번역본이 원본의 내용 을 전달하는 데 한계를 보이고 다양한 학문에서 한국어 설문 지를 개발하여 사용하고 있지만 의사소통과 장애로 인한 삶의 질을 측정하는 청각학 관련 한국어 설문지는 부족하고 개발되 어도 잘 사용되고 있지 못한 실정이다. 특히 설문 목적이 보청 기 수행능력을 평가하고자 할 때 의사소통능력과 일상생활에 서 일어나는 불편 정도를 측정하므로 언어와 문화가 다른 번역 본의 한계가 여전히 존재한다. 또한 임상에서 설문 시 목적이 다른 여러 개의 번역본을 함께 사용하는 경우가 많아 응답 시 
간이 오래 걸려 대상자의 집중력이 저하되는 불편을 초래하기 도 한다. 그러므로 여러 가지 설문 목적이 통합되고 난청인의 보청기 수행능력, 의사소통 전략, 삶의 질 등을 종합적으로 평 가하는 한국어 설문지의 개발이 필요하다. 이러한 한국어 설문 지의 개발로 난청인의 현 상황을 올바르게 측정하고 보청기 및 기타 증폭기의 효과를 적절히 평가하여 이 내용이 재활과 상담 에 반영되어 난청인의 복지가 향상되기를 기대한다.

중심 단어 : $\mathrm{APHAB}$ ·등가성·설문지·신뢰도·번역본.

\section{Ethical Statement \\ N/A}

\section{Acknowledgments \\ N/A}

\section{Declaration of Conflicting Interests}

There are no conflict of interests.

\section{Funding}

This research was supported by Hallym University Research Fund, 2018 (HRF-2018O8-OO8).

\section{Author Contributions}

All authors contributed equally to this work. T.K. and J.K. designed and performed experiments, analyzed data, and wrote the paper; T.K. designed and performed experiments in the clinic; J.K. and T.K. provided statistical analysis and critical revision; T.K. and J.K. designed experiments, analyzed data, and wrote the paper. Also, the authors discussed the results together and implications and commented on the manuscript at each stage.

\section{ORCID iDs}

Taehwa Kim

Jinsook Kim

https://orcid.org/0000-0002-9907-4266

https://orcid.org/0000-0003-3440-2393

\section{REFERENCES}

Chapman, D. W. \& Carter, J. F. (1979). Translation procedures for the cross cultural use of measurement instruments. Educational Evaluation and Policy Analysis, 1(3), 71-76.

Chu, H., Cho, Y. S., Park, S. N., Byun, J. Y., Shin, J. E., Han, G. C., et al. (2012). Standardization for a Korean adaptation of the international outcome inventory for hearing aids: Study of validity and reliability. Korean Journal of Otorhinolaryngology-Head and Neck Surgery, 55(1), 20-25.

Cox, R. M. (1997). Administration and application of the APHAB. The Hearing Journal, 50(4), 32-48.

Cox, R. M. \& Alexander, G. C. (1995). The abbreviated profile of hearing aid benefit. Ear and Hearing, 16(2), 176-186.

Cox, R. M. \& Alexander, G. C. (1999). Measuring satisfaction with amplification in daily life: The SADL scale. Ear and Hearing, 20(4), 306-320.

Cox, R. M. \& Alexander, G. C. (2002). The international outcome inventory for hearing aids (IOI-HA): Psychometric properties of the English version: El inventario international de resultados para auxiliares auditivos (IOI-HA): Propiedades psicometricas de la version en ingles. International Journal of Audiology, 41(1), 30-35.

Cox, R. M. \& Gilmore, C. (1990). Development of the profile of hearing aid performance (PHAP). Journal of Speech and Hearing Research, 33(2), 343-357.
Cox, R. M., Gilmore, C., \& Alexander, G. C. (1991). Comparison of two questionnaires for patient-assessed hearing aid benefit. Journal of the American Academy of Audiology, 2(3), 134-145.

Gatehouse, S. \& Noble, W. (2004). The speech, spatial and qualities of hearing scale (SSQ). International Journal of Audiology, 43(2), 85-99.

George, D. \& Mallery, P. (2003). SPSS for Windows Step by Step: A Simple Guide and Reference, 11.0 Update. (4th ed.). Boston, MA: Allyn and Bacon.

Guilford, J. P. \& Fruchter, B. (1978). Fundamental Statistics in Psychology and Education. New York, NY: Mcgraw-Hill.

Han, W., Lee, D., Koo, M., \& Kim, J. (2015). Questionnaires for the hearing impaired adults and elderly: A systematic literature review. Audiology, 11(1), 3-16.

Heo, J. H. \& Lee, J. H. (2009). Binaural benefit on K-HINT score for adults who use CI and HA. Audiology, 5(1), 60-70.

Hur, G. (1998). The influence of the levels of abstraction in survey questionnaires on college students' television uses and gratifications. Korean Society for Journalism and Communication Studies, 43(2). 386-428.

Jakobson, R. (1959) On linguistic aspects of translation. In Brower, R. A. On Translation. Cambridge, MA: Harvard University Press.

Jang, B. G. (2014). Translation and validation of motivation instruments in literacy research: Trends and issues. Korean Language Education Research, 49(1), 558-584.

Jeon, J. (2014). Development and construct validation of the achievement emotions questionnaire-Korean middle school science (AEQ-KMS). Journal of the Korean Association for Science Education, 34(8), 745-754.

Jeong, O. (2009). A study on equivalence in English-Korean translation (Unpublished master's thesis). Graduate School of Sejong University, Seoul.

Jo, B. H., Shin, E. Y., \& Kim, J. S. (2011). A study of validity for psychometric evaluation using attitude toward loss of hearing questionnaire (ALHQ) for the hearing impaired. Audiology, 7(1), 19-27.

Kang, H. (2013). A guide on the use of factor analysis in the assessment of construct validity. Journal of Korean Academy of Nursing, 43(5), 587594.

Kim, B. J., An, Y. H., Choi, J. W., Park, M. K., Ahn, J. H., Lee, S. H., et al. (2017). Standardzation for a Korean version of the speech, spatial and qualities of hearing scale: Study of validity and reliability. Korean Journal of Otorhinolaryngology-Head and Neck Surgery, 60(6), 279-294.

Kim, G., Lee, E., \& Kim, J. (2018). An analysis study of features for hearing aid satisfaction questionnaires: Satisfaction with amplification in daily life, client oriented scale of improvement, international outcome inventory for hearing aids. Audiology and Speech Research, 14(3), 158175.

Kim, H., Kim, J. W., Heo, J. H., Kim, D. Y., \& Sung, S. J. (2008). Content validity of aphasia screening test protocol. Communication Sciences and Disorders, 13(3), 353-380.

Kim, J. \& Lee, K. (2017). Effects on word and sentence recognition by auditory training using environmental sound for elderly hearing impaired. Audiology and Speech Research, 13(2), 115-122.

Kim, K. (2011). Likert Scale. Korean Journal of Family Medicine, 32(1), 1-2.

Kim, T., Sim, S., \& Lee, K. (2016). Development of Korean version of profile of hearing aid benefit. Audiology and Speech Research, 12(4), 209220.

Kim, Y. T. (2000). Content and reliability analyses of the preschool receptive-expressive language scale (PRES). Communication Sciences and Disorders, 5(1), 1-25.

Kim, Y. T. (2002). Content and reliability analyses of the sequenced language scale for infants (SELSI). Communication Sciences and Disorders, 7(2), 1-23.

Ko, J. (2006). A study on the realization of equivalence for the English-Korean translation (Unpublished master's thesis). Graduate School of Incheon National University, Incheon.

Kolotkin, R. L., Crosby, R. D., Kosloski, K. D., \& Williams, G. R. (2001). Development of a brief measure to assess quality of life in obesity. Obesity Research, 9(2), 102-111. 
Kolotkin, R. L., Head, S., \& Brookhart, A. (1997). Construct validity of the impact of weight on quality of life questionnaire. Obesity Research, 5(5), 434-441.

Ku, H. \& Kim, J. (2000). Test-retest reliability of the Korean hearing handicap inventory for the elderly (KHHIE). Communication Sciences and Disorders, 5(1), 1-22.

Lee, I. Y., Byun, J. Y., Kim, H., Chang, M. K., Cho, J. S., \& Cha, C. I. (2004). The application of the satisfaction with amplification in daily life scale in hearing aid users. Korean Journal of Otorhinolaryngology-Head and Neck Surgery, 47(12), 1217-1223.

Lee, K. (2004). Patterns and constrains of equivalence in translation (Unpublished master's thesis). Graduate School of Andong National University, Andong.

Lee, K. \& Shin, S. (2013). Validity of instrument development research in Korean nursing research. Journal of Korean Academy of Nursing, 43(6), 697-703.

Lee, S. (2015). A study on equivalence in English-Korean translation (Unpublished master's thesis). Graduate School of Korea University, Seoul.

Lim, H. J., Park, M. K., Cho, Y. S., Han, G. C., Choi, J. W., An, Y. H., et al. (2017). Validation of the Korean version of the abbreviated profile of hearing aid benefit. Korean Journal of Otorhinolaryngology-Head and Neck Surgery, 60(4), 164-173.

Nida, E. A. (1964). Toward a Science of Translation. Leiden: Brill.

Oh, H. A. \& Park, J. H. (2011). A study on the conception of Korean and English from the viewpoint of comparative cognitive linguistics-Focused on hearer centered expression and speaker centered expression. The Journal of Korean Language and Literature Education, 28, 1-29.

Park, H. S., Sung, S. W., Ou, S. W., Lee, K. Y., Kim, B. S., Han, J. H., et al. (2003). Development of Korean version of obesity-related quality of life scale. Journal of Obesity and Metabolic Syndrome, 12(4), 280-292.
Park, S. N., Han, G. C., Cho, Y. S., Byun, J. Y., Shin, J. E., Chu, H. S., et al. (2011). Standardization for a Korean version of hearing handicap inventory for the elderly. Korean Journal of Otorhinolaryngology-Head and Neck Surgery, 54(12), 828-834.

Pekrun, R., Goetz, T., Frenzel, A. C., Barchfeld, P., \& Perry, R. P. (2011). Measuring emotion in student's learning and performance: The achievement emotions questionnaire (AEQ). Contemporary Educational Psychology, 36(1), 36-48.

Saunders, G. H. \& Cienkowski, K. M. (1996). Refinement and psychometric evaluation of the attitudes toward loss of hearing questionnaire. Ear and Hearing, 17(6), 505-519.

Seong, T. J. (2002). Validity and Reliability. Seoul: Hakjisa Publisher.

Shabana, M., Selim, M. H., Abd El-Latif, S. M., Hamdy, M. M., \& El-Gohary, M. M. (2017). Comparison of two hearing aid fitting formulae in improving the patients' satisfaction with amplification for experienced hearing aid users. Advanced Arab Academy of Audiovestibulogy Journal, 4(1), 19-25.

Shin, J. E., Son, J. H., \& Lee, S. H. (2007, October 30). The Case Analysis of Non-Sampling Error Induced by Characteristics of Survey Questions of a Questionnaire. Statistics Korea. Retrieved from http://kostat.go.kr/ sri/srikor/srikor_pbl/1/3/index.board?bmode=read\&aSeq=382153\&p ageNo=21\&rowNum=10\&amSeq=\&sTarget=title\&sTxt=.

Ventry, I. M. \& Weinstein, B. E. (1982). The hearing handicap inventory for the elderly: A new tool. Ear and Hearing, 3(3), 128-134.

Yeo, S., Bahng, J., \& Lee, J. H. (2014). Efficacy of auditory training using sentences in noise for hearing aid users. Audiology, 10(1), 65-75.

Yun, D. H., Yoon, T. H., \& Lee, K. S. (2000). Subjective satisfaction in hearing aid users by APHAB. Korean Journal of Otorhinolaryngology-Head and Neck Surgery, 43(7), 698-702. 


\section{APPENDIX}

Abbreviated Profile of Hearing Aid Benefits Items Translate from Starkey

\begin{tabular}{|c|c|}
\hline Items & Contents \\
\hline 1 & 사람이 붐비는 채소 가게에서 계산 점원과 말할 때 대화를 따라갈 수 있다. \\
\hline 2 & 강의를 들을 때 많은 정보를 놓친다. \\
\hline 3 & 가스 검출기나 화재 경보기에서 발생하는 예기치 못한 소리가 편하게 들리지 않는다. \\
\hline 4 & 집에서 가족 중 한 사람과 있을 때 대화에 어려움을 느낀다. \\
\hline 5 & 영화관이나 극장에서 대화를 이해하기가 어렵다. \\
\hline 6 & 자동차 안에서 라디오 뉴스 청취 중 가족들이 대화를 나누고 있다면 뉴스를 청취하기가 어렵다. \\
\hline 7 & 여러 사람과 저녁 식사를 할 때, 한 사람과 대화를 하고 있는 데 대화음을 이해하기가 어렵다. \\
\hline 8 & 교통 소음이 너무 크다. \\
\hline 9 & 커다란 빈 방을 가로질러 다른 사람과 이야기할 때 말을 이해한다. \\
\hline 10 & 작은 사무실에서 인터뷰를 하거나 질문에 답할 때 대화를 따라가기가 어렵다. \\
\hline 11 & 영화관에서 영화를 보거나 활동을 할 때, 주변 사람이 소곤거리고 신문지로 바스락거려도 나는 계속 대화를 할 수 있다. \\
\hline 12 & 친구와 조용한 대화를 나눌 때 말을 이해하기가 어렵다. \\
\hline 13 & 화장실이나 샤워실의 물소리는 불쾌할 만큼 크다. \\
\hline 14 & 누군가 작은 모임에서 연설을 할 때, 모두가 조용히 경청하는 동안 나는 이해하려고 긴장해야 한다. \\
\hline 15 & 진찰실에서 의사와 조용한 대화를 하는 동안 대화를 따라가기가 어렵다. \\
\hline 16 & 여러 사람이 말하고 있을 때 대화를 이해할 수 있다. \\
\hline 17 & 건설 현장의 소리는 불쾌하도록 크다. \\
\hline 18 & 강의 시간이나 교회에서 설교를 이해하기가 어렵다. \\
\hline 19 & 군중 속에서 다른 사람들과 대화할 수 있다. \\
\hline 20 & 소방차가 옆으로 지나가면 사이렌 소리에 나는 귀를 막아야 한다. \\
\hline 21 & 종교 집회에서 설교자의 말을 따라갈 수 있다. \\
\hline 22 & 찢어지는 듯한 타이어 소리는 불쾌하게 들린다. \\
\hline 23 & 조용한 방에서 일대일로 대화를 할 때에 나는 상대방이 말을 반복하여 줄 것을 요청한다. \\
\hline 24 & 에어컨이나 선풍기가 작동할 때 다른 사람의 말을 이해하기가 어렵다. \\
\hline
\end{tabular}

